\title{
Enabling or Disabling? Reflections on the Ethiopian National WASH Inventory Process
}

\author{
Katharina Welle, Florian Schaefer, John Butterworth and \\ Kristof Bostoen
}

\begin{abstract}
The New Delhi Statement of 1990 called for universal water supply coverage by the year 2000, a goal that was later replaced by the Millennium Development Goals (MDGs) and the timeframe of 2015. As we are fast approaching this deadline, discussions are already under way for targets beyond the MDGs. In the wake of these developments, it is worth taking stock of what we can learn from existing efforts to measure access to water supply, sanitation and hygiene services. This article zooms in on one aspect of sector monitoring - national inventories - carried out in many developing countries as a first step to improve sector performance monitoring. Using the example of the National WASH Inventory in Ethiopia, under way in $2010 / 11$, as a case study, we examine possible reasons why so often these costly and human resourceintensive baselines tend to remain underutilised.
\end{abstract}

\section{Introduction \\ Since the New Delhi Statement of 1990 (United Nations 1990), which called for universal water supply coverage by 2000, we have lived through nearly two international decades for action on drinking water supply and sanitation. The New Delhi Statement was later replaced by the more modest Millennium Development Goal (MDG) to halve the world population without access to water supply and sanitation by 2015 . Alongside these international benchmarks, national and international efforts to monitor progress have grown. Under the aid effectiveness agenda, which dominates donor-recipient relationships in countries receiving large volumes of international aid, the need to measure the performance of aid has further increased, as 'measuring results' is one of the five basic principles of this agenda (OECD-DAC 2005). In the Water, Sanitation and Hygiene (WASH) sector, inventories form part of this ongoing effort to measure performance. They are often seen as a first step towards a more systematic national monitoring system that monitors results and guides future interventions. These inventories are usually costly and human}

resource-intensive. Yet, all too often, it appears that their results remain underutilised.

At a time when performance monitoring is high on the agenda, and attention is turning to post-2015 MDG monitoring, it is apt to step back and reflect on possible reasons for the underutilisation of inventory (and sector monitoring) results.

In this article, we do this by taking a close look at a current example of a resource-intensive inventory exercise, the Government of Ethiopia's National WASH Inventory (NWI). Scholars studying the political economy of knowledge production argue that power and political economy issues impede the use of information. In line with their explanations, this article will analyse the political context in which the NWI emerged and investigates to whose needs the design and implementation of the NWI responded. Then, we look ahead at the prospects for keeping the NWI up to date and for using the information based on the current capacity and WASH institutional environment in Ethiopia. 
The analysis of the NWI is based on the authors' observations from accompanying the NWI process from October 2009 to September 2011. ${ }^{1}$ It also incorporates the findings of a number of studies, training activities and workshops related to the NWI as well as the first author's PhD research.

\section{Academic literature on knowledge and power in relation to information}

There is a tendency to assume that simply providing more data on a specific issue will automatically lead to the use of this data to inform decisions (Davies 1994: 8). This technocratic view leads to a potentially restrictive focus on the visible and more easily controllable aspects of inventories - often technical and methodological issues - at the expense of the less visible processes of knowledge production and the power relations involved in that process (De Kadt 1994: 106). In the water sector, this dynamic can be observed in the focus on organising and carrying out inventories, on developing and setting up new information systems and software packages to support them, and recently, on technical innovations such as using mobile phone technology to update functionality status of water schemes. To better understand reasons for the lack of use of inventories, we must turn to the less visible processes of knowledge creation, the role of power and political economy issues.

Scholars who have studied the political economy of knowledge production give a number of explanations for the underutilisation of monitoring results. In general terms, authors observe that performance measuring can function as an instrument of control (Power 2004: 770; Davies 1994), and that processes of statistical information production and dissemination are subject to 'micropolitics' (Haggerty 2001). De Kadt, who analysed the use of information for public policy decision-making in Chile and Brazil, suggested that information systems tend to respond to the needs of those at the top of the hierarchical ladder: they determine the collection, analysis, processing and using of information, regardless of the requirements and capacities at lower levels (De Kadt 1994: 107). This analysis refers on the one hand to a 'capability trap' that inhibits the implementation of policies or programmes, a point that is also taken on by Pritchett $e t$ al. (2010) to explain implementation failures in more general terms. On the other hand, De Kadt also makes reference to information being tailored to a specific audience, which may not necessarily represent the perspectives of those tasked with implementation, generally found at lower levels of the hierarchy. Buchanan-Smith et al. (1994), who examined the lack of response to Famine Early Warning Systems in the Sahel and the Horn of Africa, found that prediction of food shortages based on severe droughts is not a problem of absolute lack of information but is rather related to institutional and logistical constraints (Buchanan-Smith and Davies 1995), i.e. questions about who has access to the information, who controls it and who owns it (Buchanan-Smith et al. 1994: 73).

It follows that, in order to throw light on the underutilisation of large-scale inventories, we need to better understand whose interests are represented in these monitoring exercises and how they relate to the wider institutional environment. The institutional environment can refer to issues of capacity but also to political and economic factors. Below, we examine the NWI process in Ethiopia through such a lens.

\section{The Ethiopian National WASH Inventory}

The Ethiopian National WASH Inventory (NWI) is a prime example of a costly and human resource-intensive monitoring activity. The NWI is effectively a household and water point census, covering a population of 83 million people living in just under 900 woredas. ${ }^{2}$ The inventory involved more than 46,000 enumerators in collecting data on water supply, sanitation and hygiene. It cost more than 80 million Ethiopian Birr (ETB), or US\$4.7 million. This represents approximately 7-9 per cent of the annual capital budget estimates for water supply (based on data between 2007 and 2009). ${ }^{3}$

We explore the dynamics underlying the NWI across three distinct phases. First, we look back at the conception of the NWI to understand the political context in which it emerged and the rationales for making it happen. We then examine aspects of the design and implementation of the NWI to understand to whose needs and concerns it responded. Finally, we look ahead to identify prospects for updating and using the NWI results, based on current capacity and institutional characteristics of the WASH sector in Ethiopia. 


\subsection{The political context in which the NUI emerged} The NWI is closely linked to a sector dialogue involving government, donors and civil society, the so-called multi-stakeholder fora held in Ethiopia since 2005, which has focused on establishing the building blocks for sector reforms. Two key elements around which the sector dialogue has revolved are increasing sector integration and harmonisation.

In the Ethiopian context, sector integration refers to creating a unified WASH programme across sub-sectors pertaining to the Ministry of Water and Energy (MoWE), the Ministry of Health and the Ministry of Education. An important agreement concerning sector integration was the 2006 Memorandum of Understanding $(\mathrm{MoU})$ between the three government ministries, which established common structures to integrate water supply, sanitation and hygiene activities. In theory, the MoU established multi-stakeholder committees at every administrative level throughout the country. In practice, these structures often remained dormant outside areas where sector integration was actively encouraged by donor or non-governmental organisation (NGO) programmes. The fact that, in Ethiopia, WASH does not refer to one sector but rather to an amalgamation of water supply, sanitation and hygiene activities across three sectors, is crucial to understand the prevailing inertia. Water supply, sanitation and hygiene represent subsectors in the case of the water and energy and health ministries and have had only marginal activities and budget shares in the education and health ministries. At the same time, their integration is regarded as critical by sector donors. Although formally in place, the WASH structures are not fully functional and are likely to remain so as long as donors continue to fund water supply, sanitation and hygiene activities through separate project structures.

The other aspect of the dialogue, 'sector harmonisation', refers to moving from the implementation of individual donor projects in water supply, sanitation and hygiene towards a programmatic approach, which foresees a single plan, budget and report for a fully integrated WASH programme coordinated by the structures established by the WASH MoU. In terms of monitoring, this requires a unified WASH Management Information System, integrating reports on water supply, sanitation and hygiene from government and donor programme interventions, but not necessarily those of NGOs. The objective of the NWI is to establish a baseline for future integrated WASH planning and for monitoring the results of this programme. As such, the NWI lays the foundation for a joint reporting, budgeting and planning system. For sector donors, decisions on future funding of a unified WASH programme are contingent on the credibility of government reporting mechanisms, so the NWI is crucial as a reliable basis for future joint WASH reporting. Its importance is also reflected in the fact that three sector donors: UNICEF, the World Bank/Department for International Development (DFID) and the African Development Bank, contributed the bulk of the direct financing of the NWI.

For the MoWE the NWI plays an important role in overcoming longstanding contentions around figures for access to water supply and sanitation in Ethiopia. The MoWE has repeatedly had differences over official water supply access figures with regional water offices but also with the Central Statistical Agency (CSA)

(Butterworth et al. 2010). The CSA's data is politically important because the agency is the authoritative source for Federal Government reporting on the MDGs. The NWI represents an opportunity for the MoWE to assert its authority over the official progress achieved in the sector. A functional monitoring system is also important in the context of the recently adopted Growth and Transformation Plan of the Government of Ethiopia, which sets demanding targets for the provision of water supply in Ethiopia (GoE 2010).

In summary, there are at least two rationales for the NWI. On the one hand, it emerges that the NWI was mainly pushed during sector dialogue platforms by external development partners and can therefore be understood as closely linked to the agenda of donors and a need to improve data to document performance of their interventions. This pressure will be even more acute should donors cede their separate reporting activities to join a programmatic approach. Whether the NWI results will be used widely therefore depends to a large degree on the future of a unified, donor-supported, WASH programme in Ethiopia. For the MoWE, on the other hand, domestic water supply is only one among several 
sub-sectors that need attention and funding, and within the Ministries of Health and Education it represents an even smaller budget share. Unified WASH reporting is not high on the agenda of the individual sector ministries. However, clarifying the 'real' coverage of access to water supply has become a concern for the MoWE that needs to reassert its authority on official figures for the sector. Contrary to sector donors, therefore, MoWE's primary interest refers to a particular moment in time, rather than the continued use and updating of NWI results. Both the MoWE and sector donors are at the top of the hierarchical ladder of monitoring WASH in Ethiopia. In the next section, we analyse how their concerns have shaped the process of designing and implementing the NWI.

\subsection{The design and implementation of the NWI}

The process of designing and implementing the NWI started in 2008. In October 2011, data collection was completed and data analysis in process. We discuss key aspects of this process, i.e. the type of data chosen and the way it was collected, aggregated and is analysed, drawing on examples from rural water supply.

In terms of the NWI design, the MoU WASH committee tasked an external consultant with the design and implementation of the NWI. This consultant, supported by two MoWE staff, was also responsible for developing regular WASH reporting formats and procedures. Given the limited human resources dedicated to the NWI, the NWI design leaned heavily on a pilot WASH inventory implemented by UNICEF in eight woredas with the aim of introducing integrated WASH planning. Both data collection formats and the choice of questions of the NWI were based on the UNICEF pilot. In consultation with the Ministries of Health and Education and the CSA, the NWI team dropped the more technical aspects of the original UNICEF formats and added questions that would help to calculate access to water in accordance with MoWE guidelines, as well as fulfilling the specific information needs of the Ministries of Health and Education and all actors at the national level. Looking at one of the data collection formats in more detail illustrates this.

The main data capturing form entitled 'safe water supply inventory for rural areas and small towns' gathers data on individual water supply schemes. The data in this form covers the type of water supply, the total number of estimated households using the scheme, the number of those households estimated to live within a $1.5 \mathrm{~km}$ radius and the yield of the scheme. The format also records non-functionality and categories of reasons for non-functionality. The information on rural water supply schemes that can be obtained based on this format relates primarily to different possibilities of calculating access based on the criteria set by the MoWE for minimum standards: namely a minimum of 15 litres per person per day within a maximum radius of $1.5 \mathrm{~km}$ from the residence of the beneficiary (MoWR 2009). By contrast, the data collection format does not provide much of the data required for day-to-day operations at the local level. For example, there is no information on the presence and functioning of user committees that are key for scheme operation and maintenance.

The data collection process was organised as a mass mobilisation exercise with the aim of collecting a vast amount of information in a short period of time. Rather than relying on water officers to collect information on water supply schemes, teachers and health extension workers were used as enumerators of both household level and water scheme data. Only in those areas where these staff were not available were water officers directly involved in the data collection. Two main concerns arise for the use and updating rural water supply scheme data. First, the assessment of water schemes by enumerators from other sectors may be more prone to data errors. This was the case in one of the UNICEF pilot woredas, where the woreda water office dismissed inventory data collected by teachers and health extension workers as incorrect. ${ }^{4}$ Second and more importantly, the water office's ownership of the data and understanding of the situation based on the data collection process may be seriously compromised. In situations where water officers had the opportunity to carry out data collection themselves, they found the activity helpful for gaining an overview of the situation in their woreda. Furthermore, visiting water schemes allowed them to conduct informal discussions with users and committee members, and to assess the sanitary condition, operation and maintenance as well as financial management of schemes and to give some quick advice where 
needed. These informal activities during data collection were seen as an important opportunity for improving day-to-day management at the local level (Welle and Bostoen 2011; Welle forthcoming 2012). The same point can be made for the arrangements concerning data entry and analysis under the NWI. Both are organised at regional level to speed up the process of obtaining NWI results.

In summary, the way the NWI was designed and implemented indicates that it is heavily geared towards the need of both federal ministries and the donor community in Addis Ababa, whose perspectives are far away from the realities of routine service delivery. The focus is hence on producing coverage data quickly at the expense of creating ownership of data and entry points for its use at the decentralised level.

\subsection{Using NWI results and keeping it up to date}

In this section, we look at the prospects for using the data beyond the immediate calculation of access figures as well as for keeping records up to date. To do so, we examine the arrangements in place for updating data and for using data to inform decentralised WASH planning.

While data entry and analysis for the NWI is carried out at regional level, the MoWE envisages that, in the future, NWI data will be migrated to the woreda level. In principle, NWI data will be accessible via the WoredaNet ${ }^{5}$ to all administrative levels, as long as offices have access to electricity, computers and the internet. In 2011, there are funds to ensure the roll-out of this infrastructure to 300 woreda-level data centres in Ethiopia, covering just over one-third of Ethiopian local governments. In theory, woredas will be responsible for updating NWI data but, in September 2011, there is still no strategy to operationalise this process.

In practice, a number of logistical and capacity issues may stand in the way of updating the NWI data at the woreda level on a regular basis.

Immediate unresolved logistical issues are the organisation and financing of training related to the introduction of the new WASH database across Ethiopia. Another very practical issue in terms of updating is that water schemes are not allocated a unique reference number and may therefore not be easily identifiable in the database once new data is collected. Other issues on updating relate to the wider operating environment at woreda level. Woreda water offices covered by sector donor programmes have received intensive capacity-building and logistical support in the form of training and the provision of hardware such as motorbikes, computers, desks and chairs to support their work. Conversely, woreda water offices without any donor back-up may lack even the most basic equipment to carry out daily tasks. Another important element for updating data is the allocation of financial resources in the form of per diems and fuel for such an exercise. Both budgetary items form part of the woreda operational budget, which is allocated by the woreda council and cannot be directly influenced by the MoWE. Previous studies suggest that operational budgets at woreda level are often very low as woreda offices may even struggle to pay their staff salaries (WSP-AF 2004: 35). This reality was confirmed for a woreda to which the authors had access. The yearly operational budget for the water office in this woreda did not exceed US\$125 during 2003-08.

Turning to the question of the use of NWI results for future integrated WASH planning and implementation at woreda level, the future channelling of WASH funds to woredas is the centre of attention. A crucial question is how many sector donors will commit their funding through a unified, government-administered channel and how many woredas will benefit from these financial resources. Looking at the current funding environment in Ethiopia, it appears likely that different financing channels will continue to operate in parallel at least for some time to come. The unified WASH programme under discussion in 2011 still foresees four different financing channels: one for woredamanaged projects, one for community-managed projects (where money is routed direct to communities through microfinance institutions), self supply and NGO projects (FDRE 2011). While it is not yet clear which sector donor programmes will join which financing channel, NGOs will continue to operate outside the unified WASH programme in the near future. To take an example, Southern Nations, Nationalities and Peoples Region with 138 woredas in 2010, had 39 NGOs and civil society organisations (CSOs) registered with WASHrelated activities, each of which operated in one or more woredas of the region (Welle forthcoming 2012). In addition, the regional government 
allocates its own funding for water supply activities in the region. Those are at least two major sources of finance outside the unified WASH programme which will impact on the planning and implementation of these activities.

\section{Conclusions}

We started the article with the puzzle that many water supply, sanitation and hygiene inventories, although implemented at a great expense, tend to remain underutilised. Scholars who have previously reflected on this issue with regard to monitoring systems have found the use of information to be intrinsically related to issues of ownership and control, and to institutional factors impeding on the use and updating of monitoring information.

A close examination of the Ethiopian NWI reveals the complexities that may stand in the way of optimally using large WASH inventory results. In Ethiopia, WASH does not stand for a sector, but for a number of water supply, sanitation and hygiene activities that span across three ministries with their own separate monitoring and reporting frameworks. Collecting WASH data in a major survey was therefore driven by sector donor programmes interested in justifying their current and future interventions through the production of reliable WASH data. The interest of the MoWE, which chiefly organised the NWI, was short term, obtaining authoritative figures of access to WASH services in the country. The design and implementation of the NWI reflects these divergent interests. The data will mainly serve to establish access figures rather than provide rich day-to-day management

\section{Notes}

1 These were carried out under the Department for International Development (DFID)-funded research programme RiPPLE. For further information, see www.rippleethiopia.org

2 Ethiopia is a Federal State organised into regional states, zones, woredas (local government areas) and kebeles (sub-local government areas).

3 The annual budget estimates are based on budget estimates for water supply published information for those responsible for WASH services on the ground. From the perspective of rural water supply, data collection and analysis were geared at achieving quick results at the expense of a learning opportunity and ownership creation at the local government level. The prospects for updating have not been thoroughly thought through and are subject to important logistical challenges. The use of the NWI data beyond creating a new statistic or two stands or falls with the implementation of the unified WASH programme.

One issue that emerges from the analysis is the mismatch between the clear bias in both the design and implementation of the NWI process towards interests at the central level, namely sector donors and the Federal Government, and the responsibilities for implementing WASH services in Ethiopia which are decentralised to the woreda level. It appears that the current focus on quickly obtaining inventory results is based on the blinkered fallacy of a linear policy process that translates access figures into allocations of financial resources towards an improvement of WASH services without contestation or conflict. However, indications are that the policy process rather follows a muddling-through, brought about by factors that are not represented in the formal NWI data and process. If it is impossible to predict all these factors, the question is whether future inventory exercises could not put more emphasis on enabling learning processes closer to the implementation level. A policy view informed by political economy can help us move towards better systems of both information and implementation.

in the Joint Budget and Aid Review (MoWR 2008: 4) and the Public Finance Review on rural water supply (World Bank 2009: 55). Financial data for this period is not very reliable, so the estimate needs to be treated with caution.

4 Interview with the woreda water office.

5 WoredaNet is a terrestrial and satellite-based network. 


\section{References}

Buchanan-Smith, M. and Davies, S. (1995) Famine Early Warning and Response - The Missing Link, London: Intermediate Technology Publications

Buchanan-Smith, M.; Davies, S. and Petty, C. (1994) 'Food Security: Let them Eat Information', IDS Bulletin 25.2: 69-80

Butterworth, J.; Welle, K.; Bostoen, K.; Chaka, T. and Goshu, A. (2010) 'Monitoring WASH in Ethiopia: Messages from a Sector Symposium', Addis Ababa: Research-inspired Policy and Practice Learning in Ethiopia and the Nile region (RiPPLE)

Davies, S. (1994) 'Introduction: Information, Knowledge and Power', IDS Bulletin 25.2: 1-13

De Kadt, E. (1994) 'Getting and Using Knowledge about the Poor (with Latin American case material)', IDS Bulletin 24.2: 100-9

FDRE (Federal Democratic Republic of Ethiopia) (2011) National WASH Implementation Framework, April

GoE (2010) 'Growth and Transformation Plan (GTP) 2010/11-2014/15', draft, Addis Ababa: Ministry of Finance and Economic Development, Government of Ethiopia

Haggerty, K.D. (2001) 'Negotiated Measures: The Institutional Micropolitics of Official Criminal Justice Statistics', Studies in History and Philosophy of Science 32.4: 705-22

MoWR (2008) Joint Budget Aid Review. Review of Financial and Performance Data for the Water and Sanitation Sector, Addis Ababa: Ministry of Water and Energy

MoWR (2009) Review of Rural Water Supply UAP Implementation and Reformulation of Plans and Strategies for Accelerated Implementation, Addis Ababa: Ministry of Water and Energy, Federal Democratic Republic of Ethiopia
OECD-DAC (2005) Paris Declaration on Aid Effectiveness, www.oecd.org/document/18/ 0,3343,en_2649_3236398_35401554_1_1_1_1, 00.html (accessed 24 November $201 \overline{1}$ )

Power, M. (2004) 'Counting, Control, and Calculation: Reflections on Measuring and Management', Human Relations 57.6: 765-83

Pritchett, L.; Woolcock, M. and Andrews, M. (2010) Capability Traps?' The Mechanisms of Persistent Implementation Failure, Center for Global Development Working Paper 234, Washington DC: Center for Global Development

United Nations (1990) New Delhi Statement, Global Consultation on Safe Water and Sanitation, 1990, www.ielrc.org/content/e9005.pdf (accessed 1 December 2011)

Welle, K. (forthcoming 2012) 'Monitoring Access to Rural Water Supply in Ethiopia' (working title), PhD thesis, University of Sussex, Science and Technology Policy Research (SPRU), Brighton

Welle, K. and Bostoen, K. (2011) What Next after Completing the First National WASH Inventory? Suggestions from Stakeholders at the National, Regional and Woreda Level, Addis Ababa: Research-inspired Policy and Practice Learning in Ethiopia and the Nile region (RiPPLE)

World Bank (2009) Ethiopia Public Finance Review, Report No 50278-ET, Washington DC: World Bank

WSP-AF (2004) Ethiopia Water Supply Sector Resource Flows Assessment, Sector Finance Working Papers 10, Nairobi: Water and Sanitation Program Africa 